\title{
BUROCRACIA PÚBLICA E PRESTAÇÃO JURISDICIONAL: O GERENCIALISMO EM PROL DAS POLÍTICAS PÚBLICAS DE ACESSO À JUSTIÇA
}

\author{
Victor Saldanha Priebe ${ }^{1}$ \\ Fabiana Marion Spengler ${ }^{2}$
}

Resumo: Com esta pesquisa busca-se fazer algumas reflexões sobre o contexto histórico da burocracia e os reflexos que este fenômeno pode causar na prestação jurisdicional. Para isto, será feita uma contextualização evolutiva de modo que, ao final, seja possível se ter claro os meios de gestão burocrática anteriormente aplicados e a vertente que atualmente se adota no país. Objetiva-se com a presente pesquisa dimensionar se o modelo burocrático aplicado na administração jurisdicional brasileira gera impactos ao princípio fundamental de acesso à justiça. Sob este contexto, será verificado se as ferramentas disponíveis para a gestão da burocracia jurisdicional estão correspondendo às expectativas.

Palavras-chave: Burocracia; Jurisdição; Gerencialismo; Políticas públicas; Reflexos.

\section{PUBLIC BUREAUCRACY AND JURISDICTIONAL PROVISION: MANAGEMENT FOR PUBLIC POLICIES FOR ACCESS TO JUSTICE}

\begin{abstract}
With this research, we seek to make some reflections on the historical context of bureaucracy and the consequences that this phenomenon can cause in jurisdictional provision. For this, an evolutionary contextualization will be made so that, in the end, it is possible to have clear the means of bureaucratic management previously applied and the current adopted in the country. The objective of this research is to assess whether the bureaucratic model applied in the Brazilian jurisdictional administration impacts the fundamental principle of access to justice. In this context, it will be verified whether the tools available for the management of jurisdictional bureaucracy are meeting expectations.
\end{abstract}

Keywords: Bureaucracy; Jurisdiction; Managerialism; Public Policy; Reflections.

\footnotetext{
${ }^{1}$ Doutorando e Mestre em Direito pelo Programa de Pós-Graduação Stricto Sensu da Universidade de Santa Cruz do Sul - UNISC. Especialista em Direito Processual Civil pela Escola Paulista de Direito - EPD. Integrante do Grupo de Pesquisas "Políticas Públicas no tratamento dos conflitos", vinculado ao CNPq. Bolsista CAPES Modalidade II. Advogado e Mediador. E-mail: victor.priebe@ @otmail.com

${ }^{2}$ Bolsista de Produtividade em Pesquisa do CNPq (Pq2). Pós-doutora em Direito pela Universitàdegli Studi di Roma Tre, em Roma, na Itália, com bolsa CNPq (PDE). Doutora em Direito pelo Programa de Pós-Graduação Stricto Sensu da Universidade do Vale do Rio dos Sinos - UNISINOS - RS. Mestre em Desenvolvimento Regional, com concentração na área Político Institucional da Universidade de Santa Cruz do Sul (UNISC). Líder do Grupo de Pesquisa "Políticas Públicas no Tratamento dos Conflitos" certificado pelo CNPq. Coordenadora da Rede de Pesquisa em Direitos Humanos e Políticas Públicas - REDIHPP. E-mail: fabiana@ unisc.br
} 


\section{1 - INTRODUÇÃO}

O presente artigo objetiva, em primeiro momento, contextualizar historicamente a burocracia pública para que se tenha um panorama evolutivo deste fenômeno social no âmbito nacional. Na sequência, será observado quais são os reflexos que o contexto atual da burocracia contribui para a inefetividade jurisdicional, fazendo menção, quando necessário, aos contextos histórico-burocráticos já vistos nesta altura do presente texto. A ligação entre a inefetividade jurisdicional e a burocracia, pretende-se fazer com a demonstração dos números fornecidos pelo Relatório da Justiça em Números realizados com a intenção de compreender os entraves e buscar contorná-los, de modo que, serão analisados o tempo morto da prestação jurisdicional e os trâmites que a burocracia exige que sejam cumpridos no decorrer do processo judicial.

Visto isto, serão trazidas à discussão as políticas públicas que visam combater a burocracia jurisdicional. Tal questão será concentrada nas Metas estabelecidas pelo Conselho Nacional de Justiça, as quais foram elaboradas em prol da efetividade da garantia constitucional de razoável duração dos processos $^{3}$, que também, em determinados pontos, combatem a burocracia jurisdicional.

\section{2 - Contexto histórico da burocracia pública}

Iniciando a breve contextualização histórica evolutiva a que o texto se propõe, pelo período que Bresser Pereira denomina de Estado Oligárquico e Patrimonial, observa-se que neste contexto a burocracia ${ }^{4}$ servia a classe economicamente dominante à época para sustentar os seus. Sendo assim, havia ali a formação de uma "nova" classe média, burocrática, composta por políticos e burocratas patrimonialistas, apropriando-se do excedente econômico

\footnotetext{
${ }^{3}$ Para que se possa estimar a razoável duração do processo, é necessário que se avalie o caso concreto, "tendo como indicativo a melhor e maior realização da garantia de acesso à justiça na perspectiva de acesso a uma resposta à questão posta qualitativamente adequada e em tempo quantitativamente aceitável“". (BOLZAN DE MORAIS,2005. p. 16).Sobre o assunto ler também (PRIEBE; SPENGLER, 2017, p.165 - 191).

${ }^{4}$ A burocracia pode ser considerada como um "sistema de organização cujo equilíbrio descansa na existência de uma série de círculos viciosos relativamente estáveis, que se desenvolvem a partir de um clima de impessoalidade e centralização". (CROZIER, 1981. p. 281). Ou, ainda, "a burocracia é uma estrutura social na qual a direção das atividades coletivas fica a cargo de um aparelho impessoal hierarquicamente organizado, que deve agir segundo critérios impessoais e métodos racionais. Esse aparelho dirigente, isto é, esse conjunto de burocratas, é economicamente privilegiado e seus membros são recrutados de acordo com regras que o próprio grupo adota e aplica". (MOTTA, 1994, p. 07)
} 
no seio do próprio Estado, e não diretamente através da atividade econômica. Nessa época, a principal função do Estado "era garantir empregos para a classe média pobre ligada por laços de família ou de agregação aos proprietários rurais" (BRESSER PEREIRA, 2001, p. 05).

Neste passo, além de controlar financeiramente as mais variadas regiões do Império, os traficantes de escravos e os senhores de terras, controlavam a partir desta atitude, a direção que o próprio Estado tomaria frente aos seus próprios interesses, pois além da dominação financeira, estava surgindo uma dominação interna do Estado por meio da burocratização dos serviços prestados por este, dos quais os servidores eram intimamente ligados à classe econômica dominante.

Também neste período, começou as ramificações desta burocratização, atingindo o Poder Judiciário da época. A magistratura era composta eminentemente de estadistas que se casavam com filhas de escravocratas ou proprietários rurais, para poderem ter condições de estudar na Universidade de Coimbra, primeiramente, e posteriormente nas Universidades de São Paulo e Olinda, e, após a conclusão dos estudos retornavam para assumir altos postos.

Este engessamento estatal, proposto pela classe economicamente dominante, fazia com que faltasse "à elite política patrimonialista brasileira do Império poder para governar sozinha. $\mathrm{Na}$ verdade o que tínhamos era uma aliança do estamento patrimonialista com a burguesia mercantil de senhores de terra e grandes comerciantes” (BRESSER PEREIRA, 2001, p. 06).

Esta condição que a classe economicamente dominante impunha à sociedade da época, dificilmente se sustentaria por muito tempo, pois o preço que esta sociedade pagava via falta de emprego, falta de educação, dentre outras obrigações estatais, acabou servindo de pilar para uma revolta da sociedade em busca de uma nova concepção de Estado.

Esta transição da concepção de Estado, denominada de Estado Autoritário e Burocrático, deu-se com a Proclamação da República o qual ficou conhecido como o primeiro golpe militar da história brasileira. Porém, esta transição não se firma a pleno por muito tempo, pois logo em sequência, a oligarquia burocrática retorna ao poder com a eleição de Prudente de Morais.

No entanto,

A transição, porém, está em marcha, e implica em uma mudança substantiva: a presença agora efetiva dos militares do Exército na aliança de poder. Era um fato novo, porque estes militares, diferentemente dos da Marinha, não podiam ser legitimamente incluídos no estamento burocrático-aristocrático do Império. Os representantes da classe média tecnoburocrática, de uma classe média burocrática moderna, que, no século XX, teria enorme expansão e diversificação, apareciam, 
assim, pela primeira vez na história brasileira por intermédio do Exército. (BRESSER PEREIRA, 2001, p. 08)

Tal instabilidade, fez com que os ideais de uma administração pública descentralizada, como era pregado no momento da Constituição da República esvaziassem-se, pois não houve neste mesmo momento uma mudança na estrutura econômica e nem ao menos na estrutura de poderes dentro desta nova República, fato este que somado com a desorganização da sociedade civil, abriram espaço novamente para a centralização do poder nas oligarquias que anteriormente já dominavam.

Esta situação, ainda em transição, não teve respaldo por parte dos militares, os quais perseguiam o ideal de ordem e progresso estampado na bandeira republicana recentemente levantada e, posteriormente, deixada de lado pelos oligarcas. Tal inconformidade militar resultou na revolução de 1930, a qual colocou no poder Getúlio Vargas.

Instituída a transição do Estado oligárquico para o Estado autoritário com Vargas, começaram a surgir as primeiras ideias vistas atualmente, como por exemplo, a valorização da competência técnica, implementadas pelo Departamento Administrativo do Serviço Público (DASP) que por sua vez fora concebido também na era Vargas. A este órgão público, era designada a função de regulamentar o

\footnotetext{
ingresso no serviço público por concurso, critérios gerais e uniformes de classificação de cargos, organização dos serviços de pessoal e de seu aperfeiçoamento sistemático, administração orçamentária, padronização das compras do Estado, racionalização geral de métodos. Além disso, o DASP cooperou no estabelecimento de uma série de órgãos reguladores da época (conselhos, comissões e institutos), nas áreas econômica e social. (BRESSER PEREIRA, 2001, p. 11)
}

Essa mudança de paradigma também se deu em decorrência da busca incansável de Vargas pelo desenvolvimento da nação, anteriormente citado, que combinado com uma falta de estrutura competente para o novo rumo que o país passa a tomar, necessitaria a estrutura burocrática de bases sólidas para sustentar o franco desenvolvimento que esta nova concepção de Estado impunha.

Porém, desde o início dos anos 60 formara-se a convicção de que a utilização dos princípios rígidos da administração pública burocrática constituíam-se em um empecilho ao desenvolvimento do país. Neste pensamento é que se baseia uma nova quebra de paradigmas na concepção de Estado burocrático nacional, pois neste momento o país necessitava de um novo modelo de Estado burocrático que molde às suas concepções burocráticas ao ritmo 
imposto pelo desenvolvimento naquele momento, sendo que este momento histórico é conhecido como Reforma Desenvolvimentista de 1967.

Tal reforma, novamente encabeçada por Getúlio Vargas, foi responsável por dirigir diversos grupos de estudos, encarregados da formulação de projetos de reforma, que objetivavam areorganização ampla e geral da estrutura e das atividades do governo.

Entretanto, é no advento do novo golpe militar em 1964 que esta reforma foi posta em prática. Sendo assim, novamente no poder,

\begin{abstract}
os militares promovem, com a ativa participação de civis, a reforma administrativa de 1967, consubstanciada no Decreto-Lei 200. Esta era uma reforma pioneira, que prenunciava as reformas gerenciais que ocorreriam em alguns países do mundo desenvolvido a partir dos anos 80, e no Brasil a partir de 1995. Reconhecendo que as formas burocráticas rígidas constituíam um obstáculo ao desenvolvimento quase tão grande quanto as distorções patrimonialistas e populistas, a reforma procurou substituir a administração pública burocrática por uma "administração para o desenvolvimento": distinguiu com clareza a administração direta da administração indireta, garantiu-se às autarquias e fundações deste segundo setor, e também às empresas estatais, uma autonomia de gestão muito maior do que possuíam anteriormente, fortaleceu e flexibilizou o sistema do mérito, tornou menos burocrático o sistema de compras do Estado. (BRESSER PEREIRA, 2001, p. 14)
\end{abstract}

Após um franco desenvolvimento, no que tange a evolução burocrática nacional, tendo-se já uma burocracia pública de alta qualidade, bem preparada, bem paga, que teve um papel fundamental na execução dos projetos de desenvolvimento, surgiram novos problemas, dos quais decorriam de um relaxamento sobre os planos de carreira que cada vez mais tinhamse por informais e flexíveis, rompendo-se assim com a própria ideia de burocracia. Chega-se então ao período histórico, denominado Retrocesso Burocrático, que carrega este nome devido à difícil transição do regime militar para a democracia. Logo,

A transição democrática foi uma grande conquista, mas teve um preço. No plano político-administrativo, a descentralização para os estados e municípios, ainda que necessária e inevitável, foi longe demais ao permitir que estes incorressem em crise financeira ao mesmo tempo que mantinha a União responsável última pelas suas dívidas. Autonomia só pode ser concedida com responsabilidade correspondente. (BRESSER PEREIRA, 2001, p. 17)

Sobre este panorama, surgem os trabalhos constituintes para a Constituição de 1988, onde o intuito que se tinha era o de centralizar no plano administrativo a autonomia das agências e empresas do Estado, recompondo-se assim o ideal burocrático de 1936. Esta concepção de Estado burocrático teve novamente uma reviravolta com a crise econômica do governo Collor em 1990, no entanto, deu os primeiros passos para orientar a atuação estatal a seguir as regras de mercado já presentes no cenário internacional naquele momento histórico. 
Não obstante, fazendo jus a característica que foi atribuída ao seu governo, Collor em atitudes equivocadas, confundiu reforma de governo com corte de funcionários e diminuição do tamanho do Estado.

Já em 1995, quando assume Fernando Henrique Cardoso, se tinha por insustentável a crise no formato do Estado burocrático desenvolvimentista, ao passo que, a solução que se apontava à época era substituir esta concepção pelas ideias globalistas de mercado, com objetivo principal de capacitação para o processo competitivo internacional. Dava-se início aqui a Reforma Gerencial.

Esta nova concepção de Estado foi desenvolvida por Luiz Carlos Bresser Pereira, o qual tentou trazer para dentro do Estado as perspectivas de regulamentação, correção e estimulação. A implementação destas novas perspectivas no Estado, pôde ser feita a partir dos três setores do Estado que se evidenciaram com a visão do gerencialismo estatal, sendo eles

o setor das atividades exclusivas de Estado, dentro do qual está o núcleo estratégico e as agências executivas ou reguladoras; os serviços sociais e científicos, que não são exclusivos mas que, dadas as externalidades e os direitos humanos envolvidos, mais do que justificam, exigem forte financiamento do Estado; e, finalmente, o setor de produção de bens e serviços para o mercado. (BRESSER PEREIRA, 2001, p. 24)

Esta reforma gerencial culminou com a criação de três instituições denominadas de agências reguladoras ${ }^{5}$, agências executivas e organizações sociais.Ao fim, percebe-se que o Estado ao adotar a reforma gerencial, entra no contexto internacional de prestação de serviços estatais dentro de uma conformidade de prestação de serviços comerciais/mercantil, no tocante à sua qualidade e efetividade.

O contexto histórico aqui disposto demonstra que, a burocracia instituída no Brasil por várias vezes teve seus conceitos distorcidos para que determinadas classes sociais ou governamentais obtivessem vantagens, ao passo que, com a reforma gerencial de Bresser Pereira, a burocracia foi utilizada de maneira que alavanque o desenvolvimento estatal e que

\footnotetext{
${ }^{5}$ No campo das atividades exclusivas de Estado, as agências reguladoras são entidades com autonomia para regulamentarem os setores empresariais que operem em mercados não suficientemente competitivos, enquanto as agências executivas ocupam-se principalmente da execução das leis. Tanto em um caso como no outro, mas principalmente nas agências reguladoras, a lei deixou espaço para ação reguladora e discricionária da agência, já que não é possível nem desejável regulamentar tudo através de leis e decretos. No campo dos serviços sociais e científicos, ou seja, das atividades que o Estado executa mas não lhe são exclusivas, a idéia foi transformar as fundações estatais hoje existentes em "organizações sociais". As agências executivas serão plenamente integradas ao Estado, enquanto as organizações sociais incluir-se-ão no setor público não-estatal. Organizações sociais são organizações não-estatais autorizadas pelo Parlamento a receber dotação orçamentária. (BRESSER PEREIRA, Luiz Carlos. 2001, p. 26).
} 
este último possa prestar os serviços que lhe são próprios com um mínimo de qualidade e eficiência.

\section{3 - Burocracia pública e seus possíveis reflexos no acesso à justiça pela perspectiva da prestação jurisdicional}

Atualmente, a sociedade passa por um momento de desacomodação com um considerável aumento do acesso à justiça ${ }^{6}$, "em contraposição a instrumentos jurisdicionais notoriamente insuficientes e ineficientes para atender e satisfazer subjetiva e objetivamente o conjunto de demandas que lhe são propostas" (BOLZAN DE MORAIS; SPENGLER, 2019).

O acesso à justiça, por sua vez, é condição sinequa non para efetividade de todos os direitos e o exercício da cidadania. ${ }^{7}$ Assim, é importante referir, que "o acesso à justiça não se esgota no acesso ao Judiciário, traduzindo-se no direito de acesso a uma justiça organizada de forma adequada, cujos instrumentos processuais sejam aptos a realizar, efetivamente, os direitos assegurados ao cidadão" (SPENGLER; SPENGLER NETO, 2013). Nesse contexto, nada adianta o livre acesso à jurisdição, se a mesma estiver envolta deconcepções burocráticas, reflexo da ineficiência da prestação jurisdicional, cada vez mais morosa.

Sob este prisma, dificilmente é confrontada a responsabilidade estatal em transformar a crise da justiça, ou crise de eficiência na prestação jurisdicional, em um não-assunto. Diante a tal situação é possível identificar tal estado de crise não como um fenômeno isolado, mas talvez como o mote central de uma tensão propagadora de ideais que sustentem reformismo na máquina estatal, não excluindo disto a organização do Judiciário.

Contudo, o estado de crise financeira que assolam países por décadas possui sua parcela de responsabilidade no contexto abordado, pois

Uma situação que dá pelo nome de crise financeira do Estado e que se foi
manifestado nas mais diversas áreas de actividade estatal e que, por isso, se
repercutiu também na incapacidade do Estado para expandir os serviços de
administração da justiça de modo a criar uma oferta de justiça compatível com a
procura entretanto verificada. Daqui resultou um factor adicional da crise da
administração da justiça. A visibilidade social que lhe foi dada pelos meios de

\footnotetext{
6 “.... o direito ao acesso efetivo tem sido progressivamente reconhecido como sendo de importância capital entre os novos direitos individuais e sociais, uma vez que a titularidade de direitos é destituída de sentido, na ausência de mecanismos para sua efetiva reivindicação. $\mathrm{O}$ acesso à justiça pode, portanto, ser encarado como o requisito fundamental - o mais básico dos direitos humanos - de um sistema jurídico moderno e igualitário que pretenda garantir e não apenas proclamar os direitos de todos". (CAPPELLETTI; GARTH, 1988. p. 11-12).

${ }^{7}$ Sobre o assunto sugere a leitura de SPENGLER, Fabiana Marion.A autocomposição como política pública de incentivo ao direito fundamental de acesso à justiça. Revista Cidadania e Acesso à Justiça. v.5, p.1 - 16, 2019.
} 
comunicação social e a vulnerabilidade política que ela engendrou para as elites dirigentes esteve na base da criação de um novo e vasto campo de estudos sociológicos sobre a administração da justiça, sobre a organização dos tribunais, sobre a formação e o recrutamento dos magistrados, sobre as motivações das sentenças, sobre as ideologias políticas e profissionais dos vários sectores da administração da justiça, sobre o custo da justiça, sobre os bloqueamentos dos processos e sobre o ritmo do seu andamento em suas várias fases. (SANTOS, 2005, p. 166)

Sob esta lógica é possível perceber que a Reforma do Judiciário, implementada pela Emenda Constitucional $n^{\circ} 45 / 2004$, traz notáveis infiltrações da lógica reformista gerencial anteriormente abordada, tanto que, a própria constituição do Conselho Nacional de Justiça reflete de maneira inequívoca a aproximação do direito com as ciências gerenciais. (NUNES; TEIXEIRA, 2013, p. 129-130)

A gestão cartorária é um bom exemplo para se demonstrar que as técnicas burocráticas não evoluíram da mesma forma que foi apresentado anteriormente, fazendo com que isto se reflita diretamente na prestação jurisdicional. O tempo dispendido ao longo dos processos judiciais, com questões burocráticas, tais como, "os prazos do cartório, do juiz e de outros membros da burocracia estatal são estimados, mas não há sanção direta pelo não cumprimento desses prazos" (SALGADO, 2007), gerando a morosidade da máquina estatal. Assim, para melhor se visualizar isto, serão expostos abaixo alguns dados obtidos no relatório Justiça em Números no ano de 2020, onde primou-se por buscar a resposta para a indagação de que: seria possível que a ineficiência na prestação jurisdicional derivaria da burocracia judicial, mais precisamente a burocracia cartorária?

Como se viu anteriormente na reforma gerencial proposta por Bresser Pereira, este conceito de burocracia pública trouxe consigo a criação de agências reguladoras e executivas, dentre outras novas modalidades de descentralização do Estado. Sob o manto desta nova concepção, destaca-se aqui, a criação do Conselho Nacional de Justiça, trazido pela Emenda Constitucional $\mathrm{n}^{\mathrm{o}} 45^{8}$, onde dispôs em seu texto o acréscimo do artigo 103-B da Constituição Federal de 1988, que regulamenta este novo órgão fiscalizador. Entretanto, apesar de algumas modificações ao longo do tempo no que tange à sucessão administrativa, as atribuições do

\footnotetext{
8 "Na ânsia de dar respostas céleres às demandas, o Judiciário brasileiro passou por uma reforma trazida pela Emenda Constitucional 45 (EC/45), cujas expectativas são de que suas alterações possam gerar transformações necessárias para implementar uma efetividade quantitativa junto ao sistema judiciário nacional." SPENGLER, Fabiana Marion. O Tempo do Processo e o Tempo da Mediação. Revista Eletrônica de Direito Processual REDP. v. 8. Periódico da Pós-Graduação Stricto Sensu em Direito Processual da UERJ. 2011.
} 
Conselho Nacional de Justiça não foram alteradas, sendo que nisto é que se pretende aprofundar no presente texto.

Contudo, a competência atribuída ao Conselho Nacional de Justiça ${ }^{9}$ que faz jus ao tema aqui tratado, é a que vem disposta no artigo 103-B, $\S 4^{\circ}$, inciso VII, da Constituição Federal de 1988. Este ditame legal, determina que devam ser elaborados relatórios estatísticos sobre os processos e sentenças de todos os órgãos que compõem o Poder Judiciário em todos os entes federativos.

Tais relatórios serviram de base para que o Conselho Nacional de Justiça elaborasse o que inicialmente se chamou de Metas de Nivelamento. A grande adesão ao projeto idealizado por este órgão fiscalizador, em prol de atribuir efetividade à garantia constitucional da razoável duração dos processos, fez com que essas metas fossem editadas anualmente, com base nos relatórios de cumprimento das metas propostas no ano anterior.A título de exemplo, para o presente ano temos as seguintes metas nacionais que o Poder Judiciário, como um todo, deve seguir:

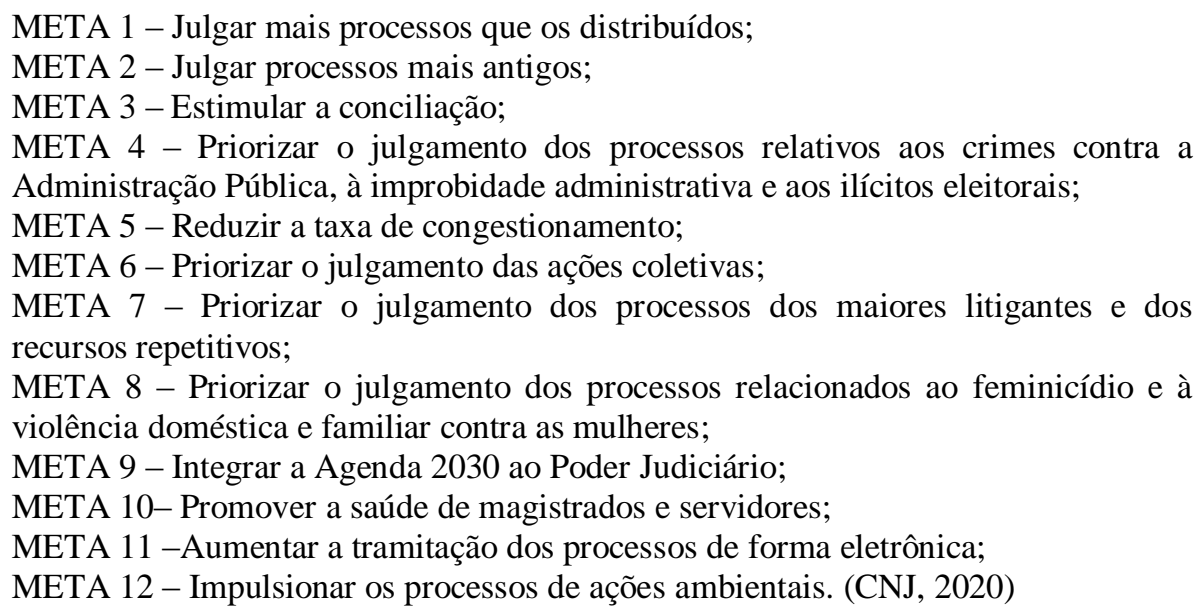

Isto se põe ainda mais claro, quando se observa o disposto pela Meta 1 de 2021 anteriormente citada. Tal meta determina que o Poder Judiciário julgue mais processos do que os distribuídos no ano vigente da meta, pois, desta forma, se estaria diminuindo cada vez mais a "fila" de processos a cada edição de metas.

\footnotetext{
$9 \S 4^{\circ}$ Compete ao Conselho o controle da atuação administrativa e financeira do Poder Judiciário e do cumprimento dos deveres funcionais dos juízes, cabendo-lhe, além de outras atribuições que lhe forem conferidas pelo Estatuto da Magistratura:

VII - elaborar relatório anual, propondo as providências que julgar necessárias, sobre a situação do Poder Judiciário no País e as atividades do Conselho, o qual deve integrar mensagem do Presidente do Supremo Tribunal Federal a ser remetida ao Congresso Nacional, por ocasião da abertura da sessão legislativa. BRASIL. Congresso Nacional. Emenda Constitucional $n^{o} 45$ de 30 de dezembro de 2004. Disponível em: http://www.planalto.gov.br. Acesso em: 20 de abr. 2021.
} 
No entanto, esta política pública com vista de trazer efetividade aos processos, os quais se identificavam uma burocracia latente e amplamente demonstrado no decorrer deste texto, também se preocupa com um dos possíveis problemas que emanam da burocracia gerencial, sendo ele a baixa eficácia dos instrumentos de responsabilização pública.

Nota-se, também, que a Meta 3 de 2021, determina que o Poder Judiciário estimule a conciliação em todos os níveis da prestação jurisdicional, estimulando os meios consensuais de solução de conflitos, assim, em 2021 deverá aumentar os percentuais de conciliação do Relatório da Justiça em Números: dois pontos percentuais na Justiça Estadual, "6\% na proporção dos processos conciliados em relação aos distribuídos" na Justiça Federal e, "aumentar o índice de conciliação em relação à média do biênio 2018/2019, em 1 ponto percentual" na Justiça do Trabalho. (CNJ, 2020, p. 2)

Por derradeiro, temos na edição anual de Metas dirigidas ao Poder Judiciário um instrumento que não garante apenas a eficácia da garantia constitucional da razoável duração dos processos, mas também, temos nelas um instrumento de combate à sensação de impunidade que a própria burocracia cartorária gera. Desta forma, agem, as metas, como mais uma arma de prevenção estatal contra a corrupção.

Se analisarmos as metas propostas pelo Conselho Nacional de Justiça ao Poder Judiciário, veremos que estas fazem parte de uma política pública estatal que visa atribuir celeridade/eficiência à prestação jurisdicional, ao mesmo tempo que pretende adequar a concepção de burocracia gerencial que atualmente se vive no Brasil.

Portanto, como bem trata Rogério Gesta Leal, em sua obra Patologias Corruptivas nas Relações entre Estado Administração Pública e Sociedade, uma vez que "não é possível compreender a administração pública burocrática divorciada do tema das políticas públicas, pois são fenômenos inter-relacionados". (GESTA LEAL, 2013, p. 172)

Desta maneira, percebe-se que as ações do CNJ, especificamente a atenção prioritária ao primeiro grau de jurisdição, o fomento em nível nacional ao tratamento adequado dos conflitos, bem como a implantação de metas de julgamento, constituem-se como "mecanismos aptos a viabilizar o maior e melhor acesso à justiça, veiculando estratégias para que o tratamento de conflitos repercuta uma ampliação da cidadania" (BOLZAN DE MORAIS; SPENGLER, 2019, p. 33), a qual se tem como fundamento do Estado democrático de direito instituído pela $\mathrm{CF}$, em seu art. $1^{\circ}$, inc. II. 
De uma maneira geral, as linhas de atuação das ações estatais mencionadas direcionam suas orientações no sentido de estabelecer uma gestão mais eficiente dos processos que tramitam no primeiro grau, pela via de uma inteligência colaborativa, o que reforça a necessidade de ser contextualizada cada linha de atuação estabelecida pela Resolução 194 do CNJ.

Neste passo, analisando o inciso I do art. $2^{\circ}$ da resolução supracitada, nota-se que neste caso a intenção primordial do CNJ é alinhar os programas, projetos e ações de todos os tribunais nacionais às suas linhas de atuação política (CNJ, 2014), as quais estão definidas pelos Macrodesafios do Poder Judiciário 2015-2020. (CNJ, 2014b)

Sendo assim, comparando as estratégias definidas pelo $\mathrm{CNJ}$, mais especificamente quanto aos desafios que tragam resultados diretos à sociedade, com o mapa estratégico definido pelo Tribunal de Justiça do Rio Grande do $\mathrm{Sul}^{10}$ (TJ/RS), percebe-se que o alinhamento pretendido está de acordo com as expectativas do CNJ, uma vez que os macrodesafios propostos por este último encontram respaldo tanto nas linhas de ação quanto nos projetos instituídos por aquele tribunal.

Outrossim, cabe ressaltar que os desafios propostos pelo $\mathrm{CNJ}$, que implicarão em resultados à sociedade, se baseiam em dois grandes pilares, dos quais o primeiro busca atribuir efetividade na prestação jurisdicional através da verificação de dados estatísticos fornecidos pelos tribunais sob as dimensões de acesso à justiça e duração do processo. $\mathrm{O}$ segundo pilar definido como macrodesafio define-se como um fomento garantidor, no plano concreto, dos direitos de cidadania, sintetizados como redução das desigualdades sociais e direitos de minorias, sem deixar de observar práticas socioambientais e sustentáveis (CNJ, 2014b, p. 3).

Em correspondência ao que foi definido pelo $\mathrm{CNJ}$ no macrodesafio que busca a efetividade na prestação jurisdicional, o TJ/RS define suas linhas estratégicas através de incremento na acessibilidade, valendo-se para isto de um atendimento de demandas sociais estratégicas, bem como programas de incentivo às práticas autocompositivas e restaurativas de amplo acesso à justiça. No que tange ao outro ponto do desafio, qual seja, a duração do processo, o TJ/RS recorre alinhas de atuação que incrementem a sua satisfação e imagem,

\footnotetext{
${ }^{10}$ Optou-se por traçar o comparativo através dos dados fornecidos por este Tribunal, pois dentre os tribunais de grande porte este é o que se tem mais proximidade com as informações fornecidas, fato que facilita a sistematização das mesmas.
} 
contando para tanto com uma otimização no gerenciamento das metas do judiciário nacional, as quais tratam sob a temporalidade processual.

Ainda sobre o alinhamento aos macrodesafios, cabe ressaltar que as linhas de atuação que o TJ/RS utilizou-se para ampliar o acesso à justiça, e cumprir com o primeiro grande desafio estipulado pelo $\mathrm{CNJ}$, também podem ser entendidas como meios de reduzir desigualdades sociais e efetivar direitos de minorias, uma vez que amplia-se o acesso ao judiciário à parcela mais desfavorecida da população para que tenham o exercício da sua cidadania assegurado pelo judiciário.

Encerrada a verificação do alinhamento por parte do TJ/RS às linhas de atuação propostas pela Resolução 194 do CNJ, percebe-se que em nenhum momento estas afetam, no sentido negativo, direitos ou garantias processuais, muito antes pelo contrário, se coadunam com princípios basilares do processo como o acesso à justiça, devido processo legal e a razoável duração dos processos.

Outro ponto que merece destaque é o fato de tal política pública não ter desconsiderado que em campos transdisciplinares, como é o caso, a realização de direitos e o seu financiamento devem ser tratados conjuntamente, tomando-se o cuidado para que um não se sobreponha ao outro. (BUCCI, 2013, p. 177) Desta forma, as questões orçamentárias "precisam estar inseridas no direito que o Estado recebeu de planejar não apenas suas contasmas de planejar o desenvolvimento nacional, que inclui e exige a efetivação de condições de exercício dos direitos sociais pelos cidadãos” (BUCCI, 2002, p. 259).

Isto pode ser identificado quando tal política pública desenvolve "em caráter permanente, iniciativas voltadas ao aperfeiçoamento da qualidade, da eficiência, da celeridade e da efetividade dos serviços judiciários da primeira instância dos tribunais brasileiros" (CNJ, 2013b, p. 16). Tal fato demonstra o entrelaçamento das proposições em busca de uma jurisdição adequada em termos qualitativos, pois se tratou de reorganizar assuntos que proporcionem efeitos diretos aos processos internos, aos recursos financeiros e recursos humanos, porém, sempre buscando que os resultados destas readequações proporcionem efeitos qualitativos concretos à sociedade, utilizando-se destes para buscar resultados quantitativos.

Sendo assim, é possível entender que a partir das orientações genéricas, as quais irradiam efeitos a outras ações do CNJ, as linhas de atuação da priorização do primeiro grau de jurisdição servem como uma estrutura que possibilitará um melhor desenvolvimento das 
demais políticas e ações já implementadas pelo CNJ, ou, que por ventura o sejam. Neste caso, contata-se um pleno funcionamento do efeito sinérgico entre as políticas públicas estruturando uma "articulação de saberes e experiências com vistas ao planejamento, para a realização e a avaliação de políticas, programas e projetos, com o objetivo de alcançar resultados sinérgicos em situações complexas" (INOJOSA, 2001, p. 105).

Neste diapasão, percebe-se que as políticas públicas instituídas pelo CNJ em prol de uma jurisdição qualitativa e quantitativamente mais adequada estão em sincronia no que tange a transposição de suas dificuldades. Como se viu anteriormente, a política de atenção prioritária ao primeiro grau de jurisdição, que direciona seus efeitos à sociedade, vem no sentido de readequar a força de trabalho e a estrutura, ao mesmo tempo em que adéqua a questão orçamentária do primeiro grau. Sendo assim, tais objetivos viabilizam, tanto em capital humano como financeiramente, a implementação das propostas trazidas pela Resolução 125/2010 do CNJ, a qual aponta seus efeitos ao cidadão.

Neste sentido, ganha relevância o papel do Estado em garantir a promoção dos métodos de solução pacífica dos conflitos, visto que esta é uma de suas missões constitucionais. Complementando, destaca Kazuo Watanabe a importância de que o "Estado estimule a criação desses serviços, controlando-os convenientemente, pois o perfeito desempenho da justiça dependerá, doravante, da correta estruturação desses meios alternativos e informais de solução de conflitos de interesses" (1988, p.133).

\section{5 - CONCLUSÃO}

Diante de tudo o que foi apresentado, fica nítida a evolução que sofreu a burocracia no Brasil, desde a Constituição do Império até os tempos de hoje. Sobre isto, pôde-se perceber, que a evolução propriamente dita, ocorreu substancialmente no pensamento dos governantes, sendo que para estes o Estado fora constituído para servi-los, e não ao contrário.

Pode-se dizer que este pensamento durou o tempo que durou, devido a baixa densidade da sociedade organizada, e sua péssima organização. A evolução demográfica da sociedade, trouxe consigo novas concepções de Estado burocrático que até o inicio do século $\mathrm{XX}$, não conseguiram efetivar plenamente suas ideias devido a grande infiltração do pensamento oligárquico nos quadros de agentes estatais. 
O pensamento burocrático somente teve suas bases modificadas com a posse de Getúlio Vargas ao cargo máximo, da já República. Vargas implementa novas concepções de Estado burocrático, rígido e altamente focado no desenvolvimento nacional, que só aconteceu com o apoio do exército e da nova sociedade organizada brasileira que aos poucos se desenvolvia. Este período de desenvolvimento burocrático e do Estado durou até a devolução do poder pelos militares à sociedade.

Ao longo desta transição, os representantes da sociedade deixaram de lado a rigidez com que os militares tratavam a questão burocrática estatal, com a justificativa de estarem preocupados com algo maior, ou seja, a crise financeira que o país enfrentava. O somatório destes dois fatores, fez com que o Estado fosse descentralizado em suas funções de Estado, e como consequência disto, com o relaxamento da burocratização, foi a ineficiência quase que total destes serviços.

Este cenário só mudou, com a implementação de agências reguladoras, fiscalizadoras e as organizações sociais, que foram criadas com o advento da reforma gerencial, já no final do século. Esta reforma trouxe à concepção de Estado burocrático que prima pelo seu desenvolvimento, não deixando de atentar-se para a eficiência e qualidade na prestação dos serviços que lhe são próprios.

Para isto, dentro dos poderes fiscalizatórios, as agências, principalmente as regulatórias, foram dotadas de poderes para punir o órgão estatal que esteja em descompasso com as prestações de serviços pretendidos, ou seja, aqui temos o Estado cortando na própria carne.

No entanto, como demonstrado no decorrer do texto, a concepção de Estado burocrático na prestação jurisdicional não evoluiu da mesma maneira que se demonstrou anteriormente. Desta maneira, o Poder Judiciário nacional é esquecido no que tange as atuações burocratizadoras que possuam os princípios da reforma gerencial.

Este cenário se modifica com o advento da Emenda Constitucional no 45 de 2004, que entre outras coisas, cria o Conselho Nacional de Justiça e atribui a este a competência de fazer um levantamento semestral do estoque de ações que tramitam pelo Poder Judiciário. Com o surgimento destes números, fica evidente que a reforma gerencial não estava, até o momento, cumprindo sua função, pois nestes dados, sobreveio a notícia de uma ineficiência cartorária que pode chegar a $95 \%$ do tempo do processo. 
A partir destas informações, o Conselho Nacional de Justiça adotou como política pública a edição de metas anuais, as quais determinam que o Poder Judiciário priorize determinados tipos de ações, das quais se verificou pelo relatório anterior que houve um maior congestionamento.

Em primeiro momento, a intenção na edição dessas metas era atribuir efetividade à garantia constitucional da razoável duração dos processos e consequente descongestionamento dos processos. Contudo, a adoção das metas também servem de arma em favor do Estado para combater a sensação de impunidade/ineficiência que a burocracia traz consigo, pois como foi tratado no desenvolvimento deste texto, já temos edições de metas que priorizam o julgamento de uma classe específica de ações, como é o exemplo das ações de corrupção e improbidade administrativa, que atualmente no cenário nacional são os crimes que mais se tem a sensação de impunidade devido a demora da prestação jurisdicional sobre eles.

Por fim, ressalta-se que a adoção das metas está cumprindo um papel importante para que se estabeleça a concepção da reforma burocrática gerencial dentro do judiciário, contudo, verifica-se que muitas dessas metas possuem redações muito abrangentes, podendo fazer com que a priorização proposta por elas, em determinados casos, fira outros direitos ou garantias constitucionais, em prol da razoável duração dos processos.

\section{REFERÊNCIAS}

BOLZAN DE MORAIS, José Luis. As crises do Judiciário e o acesso à justiça. In: AGRA, Walber de Moura. Comentários à reforma do poder judiciário. Rio de Janeiro: Forense, 2005.

BOLZAN DE MORAIS, José Luis; SPENGLER, Fabiana Marion. Mediação e arbitragem: alternativas à jurisdição. $4^{\mathrm{a}}$ ed. Porto Alegre: Livraria do Advogado, 2019.

BRASIL. Congresso Nacional. Emenda Constitucional $n^{o} 45$ de 30 de dezembro de 2004. Disponível em: http://www.planalto.gov.br. Acesso em: 20 abr. 2021.

BRESSER PEREIRA, Luiz Carlos. Do Estado patrimonial ao gerencial. In. PINHEIRO, Wilheim e Sachs (org.). Brasil: Um século de transformações. São Paulo: Companhia das Letras, 2001.

BUCCI, Maria Paula Dallari. Direito administrativo e políticas públicas. São Paulo: Saraiva, 2002. 
BUCCI, Maria Paula Dallari. Fundamentos para uma teoria jurídica das políticas públicas. São Paulo: Saraiva, 2013.

CAPPELlETTI, Mauro; GARTH, Bryant. Acesso à justiça. Tradução de Ellen Gracie Northfleet. Porto Alegre: Sérgio Antônio Fabris, 1988.

CNJ. Conselho Nacional de Justiça. Estratégia Judiciário 2020. 2014b. Disponível em: <http://www.cnj.jus.br/files/conteudo/destaques/arquivo/2015/03/7694a9118fdabdc1d16782c 145bf4785.pdf>. Acesso em: 21 abr. 2021.

CNJ. Conselho Nacional de Justiça. Metas Nacionais. Disponível em: http://www.cnj.jus.br/gestao-e-planejamento/metas. Acesso em: 20 de abr. 2021.

CNJ. Conselho Nacional de Justiça. Relatório Justiça em Números 2020. 2020. Disponível em: <https://www.cnj.jus.br/pesquisas-judiciarias/justica-em-numeros/>. Acesso em: 21 de abr. 2021.

CNJ. Conselho Nacional de Justiça. Resolução $n^{o}$ 125. 2010. Disponível em:<http://www.cnj.jus.br/busca-atos-adm?documento=2579>. Acesso em: 21 abr. 2021.

CNJ. Conselho Nacional de Justiça. Resolução no 194. 2014. Disponível em:

<http://www.cnj.jus.br/busca-atos-adm?documento=2483>. Acesso em: 21 abr. 2021.

CROZIER, Michel. O fenômeno burocrático: ensaio sobre as tendências burocráticas dos sistemas de organização modernos e suas relações na França, com o sistema social e cultural. Brasília: Editora Universidade de Brasília, 1981.

LEAL, Rogério Gesta. Patologias Corruptivas nas Relações entre Estado, Administração Pública e Sociedade.Santa Cruz do Sul: EDUNISC. 2013.

MOTTA, Fernando C. Prestes. O que é burocracia. 16 ed. São Paulo: Brasiliense, 1994.

NUNES, Dierle; TEIXEIRA, Ludmila. Acesso à justiça democrático. $1^{a}$ ed. Brasília: Gazeta Jurídica, 2013.

PRIEBE, Victor; SPENGLER, Fabiana Marion.A razoável duração do processo na Jurisdição brasileira. Revista eletrônica de direito processual, v.18, n.2, p.165-191, 2017. Disponível em: <https://www.e-publicacoes.uerj.br/index.php/redp/article/view/27010> . Acesso em: 21 abr. 2021.

SALGADO, Gisele Mascarelli. Tempo morto no processo judicial brasileiro. 2007. Disponível em: http://www.direitonet.com.br/artigos/exibir/3837/Tempo-morto-no-processojudicial-brasileiro. Acesso em: 25 abr. 2021.

SANTOS, Boaventura de Sousa. Pela mão da Alice: o social e o político na pósmodernidade. $10^{a}$ ed. São Paulo: Cortez, 2005. 
SPENGLER, Fabiana Marion. A autocomposição como política pública de incentivo ao direito fundamental de acesso à justiça. Revista Cidadania e Acesso à Justiça. v.5, p.1 - 16, 2019.

SPENGLER, Fabiana Marion. O Tempo do Processo e o Tempo da Mediação. Revista Eletrônica de Direito Processual - REDP. v. 8. Periódico da Pós-Graduação Stricto Sensu em Direito Processual da UERJ. 2011.

SPENGLER, Fabiana Marion; SPENGLER, Theobaldo Spengler Neto. O Tempo Processual Brasileiro: causa ou consequência da crise da jurisdição? v. 33 n. 2. Fortaleza: Revista do Programa de Pós-Graduação em Direito da UFC, 2013. Disponível em: http://www.periodicos.ufc.br/nomos/article/view/989/960. Acesso em: 25 abr. 2021.

WATANABE, Kazuo. Acesso à justiça e sociedade moderna. In: GRINOVER, A. P., DINAMARCO, C. R. (Coord.). Participação e processo. São Paulo: Revista dos Tribunais, 1988, p. 128-135. 